\title{
POLÍTICA, ACCIÓN ESTATAL Y BIENESTAR EN EL AGRO. BUENOS AIRES (1958-1966)
}

\section{POLITICS, STATE ACTION AND WELFARE IN THE AGRO. BUENOS AIRES (1958-1966)}

\author{
Maximiliano Ivickas-Magallán \\ CONICET/CEAR-UNQ (Argentina) \\ orcid.org/0000-0002-1646-5713
}

Recibido el 28-9-2016 y aceptado el 21-12-2016

Resumen: En las elecciones de marzo de 1958 triunfó a nivel nacional Arturo Frondizi, representante de la Unión Cívica Radical Intransigente y Oscar Alende en la provincia de Buenos Aires, quienes gobernaron hasta el golpe de Estado de 1962. En las elecciones nacionales de 1963 la victoria fue para Arturo Illia y para Anselmo Marini en el territorio bonaerense. Durante este período $-\mathrm{y}$ desde las dos décadas anteriores - se produjeron transformaciones en las conductas de los sujetos sociales agrarios de la región pampeana. El retiro urbano en la vejez, viajes con mayor frecuencia a las ciudades, un paulatino abandono de las labores físicas por parte del productor y nuevas pautas de consumo que se asemejaban a los sectores medios urbanos, fueron los cambios más sobresalientes. Sin embargo, a fines de la década de 1950, las políticas estatales orientadas al bienestar de las familias rurales eran limitadas. La propuesta de este trabajo es indagar y comparar el rol que le asignaron los gobiernos radicales de Oscar Alende (1958-1962) y Anselmo Marini (1963-1966) al bienestar de los sujetos agrarios bonaerenses; a través del análisis de las políticas públicas implementadas durante sus gestiones. Su análisis histórico permitirá establecer continuidades y rupturas respecto de «lo rural».

Palabras clave: Política, Bienestar, Agro, Buenos Aires.

\footnotetext{
Abstract: In the presidential elections of 1958 Arturo Frondizi triumphed and the same happened in Buenos Aires with Oscar Alende, both representatives of the Unión Cívica Radical Intransigente, who ruled until the 1962 coup. In the national elections of 1963 the victory went to Arturo Illia and Anselmo
} 
Marini in the Buenos Aires area. In this period and since the previous two decades, transformations occurred in the conduct of agricultural social subjects of the Pampas region. Urban retreat in old age, travel more frequently to cities, a gradual abandonment of the physical labors by the producer and new patterns of consumption that looked like urban middle class, were the most outstanding changes. However, in the late 1950s, government policies aimed at welfare of rural families were limited. This work aims to investigate and compare the role of welfare agrarian subjects in Buenos Aires assigned by the radical governments of Oscar Alende (1958-1962) and Anselmo Marini (1963-1966); through the analysis of public policies implemented during his efforts. Historical analysis will establish continuities and ruptures over «rural».

Keywords: Politics, Welfare, Agro, Buenos Aires. 


\section{Introducción}

Las políticas públicas del gobierno de Juan Domingo Perón (19461955) transformaron parte de la estructura agraria argentina, sobre todo durante los años del «peronismo clásico» (1946-1949) ${ }^{1}$. La intervención, planificación y dirigismo estatal ${ }^{2}$, aplicados desde instituciones como el Instituto Argentino para la Promoción del Intercambio (IAPI), ${ }^{3}$ el congelamiento de los arrendamientos, ${ }^{4}$ la mecanización de la cosecha del maíz ${ }^{5}$ y la transformación de una parte de los arrendatarios en propietarios, fueron elementos que aportaron al bienestar en el agro 6 . El fomento a las cooperativas agrarias ${ }^{7}$ y a las escuelas rurales,${ }^{8}$ formaron parte del entramado institucional peronista para dar respuesta a las necesidades de la familia en el campo.

En la provincia de Buenos Aires, el gobernador Domingo Mercante (1946-1952) fue el encargado de instrumentar estas políticas, estableciendo un liderazgo distinto al de Perón, donde la lealtad con el Partido Laborista fue mayor y las alianzas con la oposición política - UCR y partido Conservador -, le garantizaron estabilidad en los primeros años de gobierno 9 . Por otra parte, los dirigentes de las localidades rurales hicieron un aporte significativo en la consolidación del liderazgo de Mercante en Buenos Aires ${ }^{10}$. Más allá de estas diferencias, tanto a nivel provincial como nacional las consignas de justicia social y redistribución del ingreso fueron la base de la política económica.

El derrocamiento de Perón en septiembre de 1955, generó un escenario político complejo en la Argentina. En la esfera nacional, el general Eduardo Lonardi, apoyado por los grupos católicos de Córdoba y bajo la consigna conciliadora «ni vencedores ni vencidos» que proponía admitir a los peronistas sin Perón, no obtuvo el apoyo de otros sectores de poder y renunció a tan solo dos meses de iniciada la gestión. Triunfó el antipero-

1 Sidicaro, 2002; Torre, 2006.

2 Girbal-Blacha, 2011; Murmis y Portantiero, 2004.

3 Novick, 2004.

${ }^{4}$ Blanco, 2007.

5 Campi, 2011.

6 Azcuy Ameghino y Martínez Dougnac, 2010, p. 34.

7 Mateo, 2012.

8 Gutierrez, 2007; Jorge Navarro, 2012.

9 Aelo, 2014.

10 Salomón, 2012. 
nismo más acérrimo y la designación del general Pedro E. Aramburu dentro del gobierno que se autodenominó «Revolución Libertadora» ${ }^{11}$. Pero las tensiones que existían al interior de las Fuerzas Armadas, el poder ejercido por Perón en el exilio, el fracaso de la Junta Consultiva Nacional (1955), la presión de los partidos políticos y los sindicatos, tuvieron como resultado la convocatoria a elecciones para marzo de $1958^{12}$.

El sector intransigente de la Unión Cívica Radical - primera minoría política entre 1946 y 1955 -, se encontraba en condiciones de acceder a los principales cargos del Ejecutivo Nacional y provincial ${ }^{13}$. Sin embargo, las diferencias al interior de la corriente que controlaba la estructura partidaria -el Movimiento de Intransigencia y Renovación (MIR) - derivaron en una ruptura hacia $1956^{14}$. En las elecciones de 1958, Frondizi encabezó la lista ganadora de la Unión Cívica Radical Intransigente en los comicios nacionales - contó con el apoyo del voto peronista gracias al pacto entre Perón y Frondizi - y Oscar Alende triunfó en Buenos Aires; mientras que Balbín lideró la Unión Cívica Radical del Pueblo (UCRP), agrupación que triunfó en las elecciones nacionales de 1963 con Arturo Illia a la cabeza y Anselmo Marini en el territorio bonaerense.

Algunos investigadores provenientes de las ciencias políticas, observaron la complejidad del período 1955-1966, caracterizando al «juego político» argentino como un «juego imposible». Para ellos, la inestabilidad política era consecuencia de la ausencia de reglas explícitas o implícitas claras; y también por los intereses desencontrados entre los principales «jugadores» de este juego: las Fuerzas Armadas, los sindicatos, Perón desde el exilio y los partidos políticos. Aunque existieron matices en las interpretaciones, la explicación fue que todos estos jugadores, unidos o por separado, eran capaces de vetar los proyectos políticos de aquél que estaba en el gobierno, pero no lograban construir un consenso general con el resto de los actores gravitantes. Existía una suerte de «empate hegemónico» ${ }^{15}$.

Mientras la política mostraba tensiones e inestabilidad, existieron procesos continuistas en el funcionamiento y consolidación de institucio-

11 Spinelli, 2004.

12 Rouquie, 1981; James, 2007, p. 38.

13 García Sebastiani, 2005.

14 Gallo, 1983; Rouquie, 1975.

15 Kvaternik, 1978; O’Donnel, 1997; Smulovitz, 1986; Smulovitz, 1991; Portantiero, 1977. 
nes para el desarrollo. Entre los nuevos organismos se destacaron la creación del Instituto Nacional de Tecnología Agropecuaria (INTA) en 1956, el Instituto Nacional de Tecnología Industrial (INTI) en 1957, el Consejo Nacional de Investigaciones Científicas y Técnicas (CONICET) en 1958, la Comisión Nacional de Administración del Fondo de apoyo al Desarrollo Económico (CAFADE) en 1959, el Consejo Federal de Inversiones (CFI) ese mismo año y el Consejo Nacional para el Desarrollo (CONADE) creado en 1961. Otra línea de continuidad tanto a nivel nacional como provincial fue la reivindicación discursiva sobre la necesidad de un debate impositivo y la reforma agraria, temas presentes en la agenda pública al menos desde $1930^{16}$.

Durante este período también se produjeron transformaciones en las conductas de los sujetos sociales agrarios de la región pampeana. La familia y las condiciones de bienestar en la provincia de Buenos Aires presentaban algunas características diferenciales con los años previos. El retiro urbano en la vejez, viajes con mayor frecuencia a las ciudades, un paulatino abandono de las labores físicas por parte del productor - que se inclinaba cada vez más por las actividades gerenciales - , y nuevas pautas de consumo que se asemejaban a los sectores medios urbanos, ${ }^{17}$ fueron los cambios más sobresalientes ${ }^{18}$.

Estas condiciones de mayor bienestar en el agro pampeano no fueron casuales. Las denominadas consignas del «Welfare State», que durante más de veinticinco años permearon las decisiones políticas, económicas y sociales de los países desarrollados en la posguerra, tuvieron su correlato en las zonas en vías de desarrollo. En América Latina prevalecieron las consideraciones cepalinas vinculadas al desarrollo, aunque se combinaron con políticas de pleno empleo y aumento del gasto fiscal, medidas propias de la orientación keynesiana. En líneas generales el «Welfare State» o Estado del Bienestar se propuso garantizar un conjunto básico de elementos materiales para mejorar las condiciones de vida de la sociedad. Sin embargo, existen diferencias a la hora de definirlo conceptualmente.

Algunos autores sostienen que el Estado del bienestar «ha de respetar la forma de funcionamiento del sistema económico» y se limita a «una distribución horizontal dentro del grupo de los trabajadores dependientes, mientras que no se toca la estructura patrimonial de clase ni el reparto de

\footnotetext{
16 Lattuada, 2008; Blanco, 2007; Lázzaro, 2014.

17 Adamovsky, 2009.

18 Balsa, 2004, pp. 280-285.
} 
la propiedad», generando así una «contradicción» entre objetivo y método $^{19}$. Otros proponen que el Estado del Bienestar actuó como «formula pacificadora de las democracias capitalistas avanzadas» y consistió «en la obligación explícita que asume el aparato estatal de suministrar asistencia y apoyo (en dinero o en especie) a los ciudadanos que sufren necesidades y riesgos específicos característicos de la sociedad mercantil $»^{20}$. Esta interpretación sobre su origen histórico posiciona al welfare state como un «estabilizador» de las tensiones en las democracias liberales.

Una tercera línea analítica propuso al welfare state como «un sistema político que organiza, programa y controla el desarrollo económico a través de un conjunto multifuncional de instituciones políticas y administrativas», entre las que se encuentran el crédito, la política fiscal, el empleo, la educación, la previsión social, etcétera ${ }^{21}$. Sin embargo, estos marcos conceptuales resultan incompletos para comprender la situación de países periféricos, como es el caso de la Argentina, donde la falta de consensos entre los sectores de poder derivó en una fragilidad política e institucional que duró más de medio siglo. La complejidad aumenta cuando se piensa en un territorio y período específico, como lo fueron los sectores rurales de la provincia de Buenos Aires entre 1958 y 1966.

La heterogeneidad y multiplicidad de propuestas para mejorar su vida cotidiana, se observa en las discusiones parlamentarias, en informes técnicos oficiales y en publicaciones periódicas de la época. Proyectos de infraestructura básica (caminos, electricidad, agua potable), solicitudes de creación de centros de salud y educación, reglamentaciones que garanticen la estabilidad del productor en la tierra, ingresos acordes a los niveles de actividad, instituciones rurales que garanticen el acceso a la ciencia y la técnica moderna y la posibilidad de insertar la producción en el circuito comercial, fueron algunos de los temas más recurrentes.

La propuesta de este trabajo es indagar y comparar el rol que le asignaron los gobiernos radicales de Oscar Alende (1958-1962) y Anselmo Marini (1963-1966) al bienestar de los sujetos agrarios bonaerenses; a través del análisis de las políticas públicas implementadas durante sus gestiones. Interesa, en ese sentido, reconocer las especificidades que tienen los programas, propuestas y declaraciones de intención de estos dos gobernadores. La cuestión política atraviesa el análisis de estos dos líderes

\footnotetext{
19 Habermas, 1988, p. 124.

20 Offe, 1990, p. 135.

21 Picó, 1990, p. 21.
} 
provinciales pertenecientes a fracciones opuestas de un mismo partido. $\mathrm{Su}$ análisis histórico permitirá establecer continuidades y rupturas políticopartidarias respecto de «lo rural», en un período que - todavía - tiene a la propiedad de la tierra en el centro del debate.

La hipótesis que orienta esta investigación supone que el Estado provincial no poseía instrumentos e instituciones regulares en las décadas de 1950 y 1960 para acercarse con mayor precisión a problemáticas históricas de la vida cotidiana de los actores rurales. Aunque existieron esfuerzos para problematizar y dar respuesta a estas cuestiones, fueron inconsistentes y no tuvieron sustentabilidad en el tiempo. La falta de consenso con el resto del arco político, sumado a las debilidades político-electorales de los gobiernos radicales afectaron los proyectos de mejora del bienestar en el mediano y largo plazo para el agro bonaerense.

\section{Políticas agrarias en las presidencias de Arturo Frondizi y Arturo Illia (1958-1966)}

El triunfo de Arturo Frondizi en las elecciones de 1958 le permitió a la coalición desarrollista que apoyó a la Unión Cívica Radical Intransigente - también conocido como Frente Nacional,$-{ }^{22}$ gestionar un programa político para el desarrollo. Entre las principales consignas electoralistas en materia agraria se destacaron la colonización y la reforma agraria $^{23}$. Estabilización y desarrollo fueron las bases del plan político nacional ${ }^{24}$. En su diagnóstico para recomponer la economía del país, los funcionarios de la cartera de Agricultura y Ganadería sostuvieron que el sector industrial restó fuerza de trabajo al sector rural «y éstos no fueron sustituidos por procedimientos técnicos modernos tendientes a sostener e incrementar niveles productivos» 25 .

Durante la campaña electoral y en el inicio de su gobierno, Frondizi defendió la reforma agraria y la asoció a dos grandes propósitos: por un lado el bienestar general, que implicaba «aumentar la producción rural en beneficio colectivo»; por otro, arraigar al productor a la tierra, otorgando posibilidades «de vida en el campo a personas dispuestas a estable-

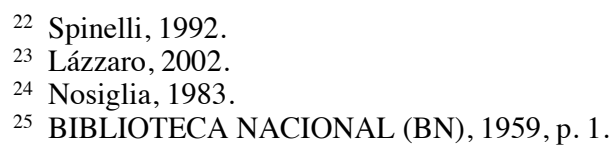


cerse allí; cuyo establecimiento redunde en bienestar general y que sin la reforma se vean impedidos de hacerlo» ${ }^{26}$. En la práctica, el gobierno de Frondizi intentó una reforma agraria moderada de carácter tributario, distanciándose al inicio de la década de 1960 del discurso beligerante característico en sus inicios ${ }^{27}$. Junto a sus colaboradores, Frondizi apostaba a una política estabilizadora con un marcado orden de prioridades, en donde el petróleo y el acero eran centrales, porque actuarían como «base fundamental del desarrollo de la industria ligera, proveedora, más que nada, de maquinarias agrícolas, inevitables si se quiere lograr una agricultura tecnificada y altamente productiva» ${ }^{28}$.

En lo respectivo al debate sobre la estructura de tenencia de la tierra, los expertos del gobierno nacional reorientaron el discurso reformista en función de las necesidades políticas y de la coyuntura económica. Los nuevos argumentos planteaban que los repartos de tierra «aún los más radicales, no pueden mejorar un ápice la suerte de la inmensa mayoría de la población argentina» y que la mayoría de la población «sólo puede ser afectada por la «reforma agraria» que logre aumentar la masa de bienes que la tierra puede dar a la colectividad nacional» 29 . Para justificar el viraje ideológico en los temas agrarios, la UCRI realizó en 1961 la Convención de Chascomús, que incorporó a la doctrina radical los conceptos de eficacia, eficiencia y tecnificación de las labores. Sobre estos criterios, afirmaban que la mejor reforma era «la tecnificación del trabajo agrícola, que en algunos países modernos ha permitido aumentar la producción como si la tierra fuese mucho más extensa» ${ }^{30}$.

A pesar de haber impulsado una estrategia económica y política nacional en sintonía con los postulados elaborados por la CEPAL durante este período, el desarrollismo no logró contener el frente interno. Las tensiones con los partidos políticos opositores, Perón desde el exilio, el sindicalismo y las Fuerzas Armadas, alcanzaron su nivel más alto luego de las elecciones provinciales bonaerenses celebradas e1 18 de marzo de 1962, en las que triunfa la fórmula peronista Framini-Anglada. El resultado, inesperado para el oficialismo, obligó a Frondizi a intervenir la provincia para salvar su gobierno aunque no fue suficiente y el 29 de marzo

\footnotetext{
${ }^{26} \mathrm{BN}, \mathrm{s} / \mathrm{f}, \mathrm{p} .1$.

27 Lázzaro, 2002.

28 Nosiglia, 1983, p. 33.

$29 \mathrm{BN}, \mathrm{s} / \mathrm{f}, \mathrm{p} .21$.

$30 \mathrm{BN}, \mathrm{s} / \mathrm{f}, \mathrm{p} .22$.
} 
las Fuerzas Armadas, quienes vieron peligrar los objetivos logrados en la revolución septembrista, derrocaron al gobierno intransigente ${ }^{31}$.

La asunción del Presidente del Senado José María Guido como primer mandatario, fue la alternativa semidemocrática elegida para evitar otra crisis institucional y otorgarle legalidad a un proceso político deslucido $^{32}$. La complejidad política generada por la nueva proscripción del peronismo, hizo inminente la convocatoria a elecciones, fijada para julio de 1963. La fórmula de la UCRP encabezada por Arturo Illia triunfó con un $25 \%$ de los votos, en una elección que tuvo como protagonista al voto en blanco, que superó el 20\% de los sufragios. Esta debilidad acompañó al radicalismo del pueblo durante toda su gestión.

El gobierno de Arturo Illia estuvo condicionado por el sector militar, los partidos políticos opositores y el sindicalismo peronista, situación análoga a la que debió enfrentar Frondizi previamente. La reactivación económica fue una consigna central y se instrumentó a través del fomento al consumo, aumento del salario real y aumento de las exportaciones agropecuarias. La aplicación de la Ley del Salario Mínimo, Vital y Móvil en 1964 ilustra el perfil adoptado por el radicalismo del pueblo. En este período «el producto bruto industrial siguió creciendo, los salarios se elevaron por encima de la inflación, y el desempleo se redujo del $8,8 \%$ en julio de 1963 a un 4,6\% en octubre de 1965»; pero también existieron limitaciones serias, entre ellas «resolver la ineficiencia de muchas empresas estatales ${ }^{33}$.

En 1963 la Secretaría de Agricultura y Ganadería de la Nación publicó un informe con el programa agrario para el período 1963-1969, que proponía reactivar la economía y reordenar la estructura económica en los siguientes aspectos: «1. Régimen impositivo; 2 . Crédito agrario; 3 . Tenencia de la tierra; 4. Capacitación técnica; 5 . Reajuste de la política de desarrollo industrial; 6 . Previsiones y medidas frente a un posible marcado incremento de la producción agropecuaria» ${ }^{34}$. El diagnóstico realizado por los funcionarios nacionales también consideraba las desigualdades regionales y distinguía la zona pampeana del interior del país. Según la Secretaría de Agricultura y Ganadería de la Nación, fueron 21 los factores que condicionaron negativamente la actividad agropecuaria:

\footnotetext{
31 Rouquie, 1981.

32 Tcach, 2007, p. 38.

33 Tcach y Rodríguez, 2011, p. 96.

34 Kugler, 1963, pp. 1-2.
} 
«1. Paulatina destrucción del Patrimonio fundamental: el suelo; 2. Enseñanza agrícola estancada y en algunos aspectos anacrónica; 3. Desarrollo inarmónico de la economía del país; 4. Proteccionismo indiscriminado a la industria y distorsión en el desarrollo agropecuario; 5. Falta de equilibrio en la capitalización del sector agropecuario; 6 . Política impositiva contraproducente; 7. Crédito limitado a la actividad rural; 8. Mayores precios no se tradujeron en aumentos de la producción; 9. El proceso de la subdivisión de la tierra se ha detenido; 10. Las leyes de arrendamiento en vigencia no estimulan una mayor productividad; 11. Acción colonizadora limitada; 12 . Reducción de superficie dedicada a la producción agrícola; 13. Estancamiento o disminución de la densidad ganadera; 14 . Tendencia negativa de los rendimientos unitarios de los principales cultivos de la región pampeana; 15 . Reducción de la producción de carne bovina por unidad animal; 16. Baja rentabilidad de la empresa agropecuaria; 17. Reducción del salario rural; 18. La producción por habitante rural es relativamente baja; 19. Producción a altos costos; 20. Pérdidas de mercado o difícil colocación de cosechas por falta de calidad; 21 . Reducción de saldos exportables» ${ }^{35}$.

Al minucioso diagnóstico anterior se agregó el del Consejo Federal de Inversiones: «las posibilidades de intensificar el uso de la tierra en las empresas multifamiliares depende de la división de la tierra en propiedad o de los cambios en el manejo de capital y trabajo o de ambas cosas, en las explotaciones actuales» ${ }^{36}$. El diagnóstico no era erróneo, pero las disposiciones fiscales y tributarias no apuntaron a desestructurar este tipo de especulación.

Las medidas más destacadas para el agro fueron el Plan Nacional de Transformación Agraria, instrumentado a través del decreto N. ${ }^{\circ} 4403$ y los Programas de Desarrollo Agropecuario (1965), enmarcados en el Plan Nacional de Desarrollo (1965-1969). El primero contemplaba la posibilidad de los arrendatarios para adquirir la tierra que trabajaban, haciendo una oferta económica al propietario por el lote explotado para adquirirlo en propiedad. En esto no fue la cuestión social lo que motivó la transformación sino la necesidad de modernizar el agro.

Por otra parte, el Plan Nacional de Desarrollo y los Programas de Desarrollo Agropecuario (1965) sobre pasturas, fertilizantes, conservación de suelos, sanidad animal y vegetal, desarrollo forestal, colonización, en-

\footnotetext{
35 Kugler, 1963, pp. 1-16.

36 CONSEJO NACIONAL DE DESARROLLO (CONADE), 1964, p. 38.
} 
señanza agropecuaria y comercialización, estaban atravesados por el discurso modernizador. Éste era vinculado, a su vez, con las mejoras en los rendimientos de la producción y un consecuente incremento de la rentabilidad económica ${ }^{37}$. El Estado otorgaba incentivos económicos para los productores que asimilaban estas prácticas en sus explotaciones. El incremento de la productividad era una cuestión central en los planes agrarios y para el caso de la fertilización de pasturas, «los ensayos indican que se lograría un aumento de $39 \%$ y $55 \%$ en los rendimientos en forraje, con aplicaciones de fósforo y nitrógeno respectivamente» ${ }^{38}$.

Las concepciones sobre la colonización y la redistribución de la tierra también fueron redefinidas a mediados de 1960. Para los expertos de CONADE, los colonos no reclamaban sólo la tierra en propiedad, sino también «otra serie de circunstancias relacionadas con los medios de producción y las formas de vida» ${ }^{39}$. La generalización de la cosecha mecánica, el aumento en la cantidad y potencia de los tractores y las mejoras en los implementos y sembradoras de origen nacional, trasformaron la fisonomía del agro, sobre todo en la región pampeana ${ }^{40}$. La migración del campo a la ciudad, el crecimiento del trabajo asalariado y una mayor oferta de contratistas de siembra y/o cosecha, también formaron parte de las transformaciones sectoriales que produjeron las políticas «de desarrollo» ${ }^{41}$.

La eficiencia era concebida como un valor en sí mismo en los informes técnicos para el desarrollo agropecuario. La modernización pensada desde el Estado proponía intensificar la tecnología antes que la mano de obra, lo que se traduce en niveles más elevados de capitalización para acceder o estar lo más cerca posible del umbral tecnológico. Si se acepta la validez de este supuesto, los conceptos que sustentaban el programa de colonización en la esfera nacional pusieron por encima del bienestar de los sujetos agrarios a la productividad. Lo mismo sucedió con las propuestas de mecanización y de manejo racional de los suelos. La introducción de un número mayor de tractores, sembradoras, cosechadoras e implementos y del uso de herbicidas y fertilizantes, permiten observar la importancia de producir más y reducir costos a través de la incorporación de nuevas tecnologías.

\footnotetext{
37 Girbal-Blacha, 1998, pp. 75-84; Barsky y Gelman, 2009, pp. 389-426.

38 CONADE, s./f., p. 23.

39 CONADE, s./f., p. 61.

40 Campi, 2011, p. 156.

41 Balsa, 2006.
} 
Las dos administraciones radicales que gobernaron el Estado nacional entre 1958 y 1966, promovieron y construyeron un discurso que buscaba destacar las consignas de desarrollo en el agro y en el sector industrial, sobre la base de la eficacia y la eficiencia. A diferencia de lo acontecido en las democracias liberales europeas, la intransigencia radical y el radicalismo del pueblo no fueron capaces de consensuar fórmulas pacificadoras de las tensiones políticas generadas luego del derrocamiento de Perón en 1955. Los «jugadores políticos» con capacidad de veto no articularon una «fórmula ${ }^{42}$ que les permita dirimir las tensiones políticas y económicas características de la puja distributiva. En este marco histórico, las políticas públicas orientadas al bienestar en el agro fueron difusas, inconsistentes y por momentos contradictorias.

\section{Políticas públicas y bienestar en el agro bonaerense}

Oscar Alende y la intransigencia radical (1958-1962)

En 1958 triunfó en las elecciones provinciales la fórmula intransigente de Oscar Alende ${ }^{43}$-Arturo Crosetti con el 49,1\% (1.321.041 votos), frente a la fórmula del «radicalismo del pueblo» encarnada en Crisólogo Larralde-Ricardo Rudi con el 28,6\% (769.655 votos). El plan de gobierno desarrollista en Buenos Aires se asentó en tres pilares: vialidad, energía y reforma agraria/tributaria ${ }^{44}$. El proyecto «integral» destinó también importantes recursos en salud y no fueron despreciables los cambios en materia educativa ${ }^{45}$. El fomento a la profesionalización de sus funcionarios fue otra iniciativa para mejorar la gestión pública. La creación de la Junta de Planificación Económica de la Provincia de Buenos Aires ilustra esta cuestión ${ }^{46}$.

42 Smulovitz, 1991.

43 Oscar Alende: cirujano y político. Nació el 1 de julio de 1909 en Maipú, provincia de Buenos Aires. Cursó estudios en la Facultad de ciencias médicas de Buenos Aires y ejerce su profesión en Banfield. Perfeccionó sus conocimientos quirúrgicos en los Estados Unidos. Fue presidente del Centro de estudiantes de medicina. Fue diputado provincial (1948-1952); diputado nacional (1951-1955) y gobernador de la provincia de Buenos Aires (1958-1962). (Abad de Santillan, 1956, p. 109)

44 Lázzaro, 2008.

45 Panela, 2014, p. 98.

46 Stropparo, 2012; Bayle y Diez, 2006. 
Encabezada por el Ministro de Economía Aldo Ferrer ${ }^{47}$, asesoró en una multiplicidad de temas al ejecutivo provincial y tuvo a su cargo la coordinación, desarrollo y ejecución de políticas públicas ${ }^{48}$.

En materia de política industrial, la provincia estuvo condicionada para impulsar un proyecto autónomo porque el gobierno nacional estableció una política industrial descentralizadora. Si bien la Capital Federal y el conurbano concentraban buena parte de la producción industrial, algunos autores afirman que este número desciende entre 1958 y 1964 «mientras que creció la participación de las provincias de Córdoba, Santa Fe y especialmente del interior de Buenos Aires, que pasó del 10\% al 13\% del total» ${ }^{49}$.

Para Alende la estructura de tenencia de la tierra fue uno de los elementos centrales de conflicto en la provincia de Buenos Aires. A diferencia de lo acontecido en la década de 1940, cuando las consignas de reforma agraria y colonización fueron las principales respuestas estatales a la «cuestión rural» - aunque no fueron las únicas - , el desarrollismo intentó modificar estos preceptos por los de previsibilidad y estabilidad; con la pretensión de atender las demandas no resueltas durante el peronismo, pero sin perder de vista su legado de justicia social. De las contradicciones no resueltas durante el peronismo en la distribución de la tierra se pasó a un período en el que las principales tensiones se dieron por el proceso de modernización agraria.

El sector rural ocupó un lugar central del discurso político y durante los primeros meses como gobernador, Alende encaró una gira por la provincia, recogiendo las principales preocupaciones y reclamos de los productores rurales ${ }^{50}$. En 1959 pronunció un importante discurso en la localidad de Rojas titulado «Reforma agraria», ${ }^{1}$ asunto largamente postergado en la historia argentina. El Ministro bonaerense del ramo, Bernardo

47 Aldo Ferrer: nació en el año 1927. Economista y político argentino. Doctor en Ciencias Económicas recibido en la Universidad de Buenos Aires en 1953 con su tesis doctoral «El Estado y el Desarrollo Económico» publicada en 1956. Funcionario de la Secretaría de las Naciones Unidas (1950-1953) y agregado económico de su país en la embajada de Londres en 1956, fue Ministro de Economía y Hacienda de la Provincia de Buenos Aires, 1958-1960. Datos extraídos de la enciclopedia virtual Eumed: http://www.eumed net/ cursecon/economistas/ferrer.htm

48 Rougier, 2015.

49 Rougier, 2014, p. 127-128.

50 DIRECCIÓN DE PRENSA, 1958.

51 GOBIERNO DE LA PROVINCIA DE BUENOS AIRES, 1959. 
Barrere, afirmó que, «no es nuestro deseo subestimar el cometido industrial del país, ni dejar de auspiciarlo, por la misma razón de su desarrollo incipiente. Pero es en la esfera agraria, donde ya está consolidado el menester nacional, donde desde hace mucho se palpan los frutos generosos de la consagración argentina ${ }^{52}$. Expropiaciones moderadas y colonización rural se combinaron para enfatizar las reformas en el agro.

Existieron otras políticas estatales en beneficio del sector agrario, como el proyecto de ley complementario al de reforma agraria, que permitía a las comunas establecer zonas de carácter económico-social para que el Ejecutivo provincial promueva «regímenes de colonización en las tierras afectadas a ese desarrollo» ${ }^{53}$. También se otorgaron créditos hipotecarios a través del Banco de la Provincia de Buenos Aires que podía ser usado para cancelar el total de las deudas contraídas a una tasa de interés no mayor al $6 \%$ anual, amortizable en no menos de diez años ${ }^{54}$.

Con estas medidas, Oscar Alende intentaba contener las demandas redistributivas de los sectores populares. Una parte de la bibliografía sostiene que en Buenos Aires «lo que se quiere extirpar es el gran latifundio, exclusivista, absorbente y retrógrado a fin de que sus tierras cumplan con una función social y económica» ${ }^{55}$. Los beneficios del accionar estatal bonaerense también alcanzaron al cooperativismo. El apoyo del Ministerio del área para dar origen a nuevas cooperativas y el acceso al crédito a tasa subsidiada $-4 \%$ anual - , resultaron verdaderos incentivos para estimular e incrementar la producción ${ }^{56}$.

Las decisiones estatales orientadas hacia el agro en la experiencia desarrollista bonaerense fue distinta respecto de lo que sucedía a nivel nacional, donde la cuestión rural quedó relegada a un lugar secundario de la macroeconomía. En las discusiones parlamentarias provinciales se percibe la preocupación de los diputados por el arraigo del productor y por evitar la migración del campo a la ciudad. A raíz de una moción presentada por el diputado Illia en mayo de 1958, se observan cuestiones que exceden a la obtención de la tierra:

52 Asuntos Agrarios, 1958, p. 3.

53 Asuntos Agrarios, 1958, p. 1.

54 Zarrilli, 1998.

55 Lázzaro, 2008, p. 91.

56 El texto de la norma se encuentra disponible en la página web del Ministerio de Jefatura de Gabinete de Ministro de la provincia de Buenos Aires: http://www.gob.gba.gov. ar/legislacion/legislacion/l-6022.html 
«decir cómo se debe distribuir la tierra entre sus hijos y como, en nuestra Provincia, el campo debe tener las mismas perspectivas para la lucha y las mismas visiones del porvenir y esperanza de todo el pueblo argentino; para que nuestros hombres no se vayan del campo y para que nuestros hijos no se vayan del campo y para que nuestros hijos no vengan a la ciudad a aumentar el problema pavoroso de la vivienda» ${ }^{57}$.

Las políticas públicas estaban sustentadas en la prórroga de los contratos de arrendamiento, la suspensión de los desalojos y la colonización, que actuaron como contención pero no como solución a la problemática de la cuestión social rural. Algunas voces de la dirigencia recordaban que mejorar las condiciones de vida en el agro no sólo impactaría en la productividad; también haría lo suyo en las tensiones generadas por la modernización, siendo la migración y la vivienda tópicos destacados. Lo que no explicitaba la dirigencia eran las «contradicciones»-propias del Estado del Bienestar del período de posguerra - generadas por estas consignas $^{58}$. Introducir mejoras suponía mayores erogaciones fiscales, que derivaban en un aumento de la presión fiscal sobre los sectores productivos y/o un aumento del déficit fiscal.

Durante el período desarrollista, el Estado otorgó incentivos fiscales para fomentar el ahorro interno y la inversión extranjera directa orientados a las industrias de capital intensivo. Por otra parte, las transformaciones también alcanzaron al sector agropecuario, que atravesó un proceso de mecanización y tecnificación de la producción. La intervención del Estado en la economía para mejorar las condiciones de vida de los sectores rurales, aumentar la productividad en el agro y profundizar el desarrollo industrial en forma simultánea generó tensiones que derivaron en proyectos inconclusos o truncos.

En este sentido, el interior provincial adquirió notoriedad en los discursos parlamentarios. La infraestructura vial fue un reclamo recurrente en el gobierno de Alende, sobre todo entre 1958 y 1960. Pavimentación y apertura de nuevos caminos fueron las solicitudes más frecuentes, asociadas por lo general a la cuestión productiva. Las declaraciones y los proyectos de ley presentados en la Cámara de Diputados provincial ilustran esta cuestión. Localidades ubicadas en el norte de la provincia como Baradero, Carmen de Areco y Salto; en el centro como Bragado, Nueve de Ju-

57 Cámara de Diputados de Buenos Aires (CDBA), 1958, p. 101.
58 Offe, 1990. 
lio y Tandil; en el centro-oeste como Rauch y Las Flores; y en el suroeste como Tornquist y Olavarría - entre otros - , presentaban a través de sus representantes parlamentarios los reclamos y solicitaban soluciones.

Los fundamentos planteaban la importancia de unir las principales zonas productivas de la provincia, como eran las localidades de Nueve de Julio y Salto, ubicadas en el centro-oeste de la provincia. La pavimentación del camino para conectarlas suponía una movilización más eficaz de la producción, que había crecido en su volumen: en el caso de la ganadería en 1950 se contaban 92.851 cabezas de ganado vacuno y 30.000 porcinos; para 1956 eran 115.332 las cabezas de ganado vacuno y 52.087 los porcinos ${ }^{59}$.

Similares ideas esbozaron los diputados Aramburu y Daoud cuando presentaron un proyecto de construcción del camino para unir las localidades de Tandil y Las Flores, ubicadas en el centro de la provincia: «este camino por su trazado viene a romper la vieja estructura colonialista del abanico del transporte convergente en la Capital Federal y tiende a conectar a una importante zona de la Provincia con los puertos de ultramar del sur de la misma (Mar del Plata, Necochea, Bahía Blanca)» ${ }^{60}$.

En otros casos, la cuestión de los caminos apuntaba a comunicar Buenos Aires con otras provincias de la región pampeana. El proyecto presentado en 1960 por el diputado Crasso, proponía la construcción de un camino que uniera la localidad de Teodolina, ubicada al sur de Santa Fe, con el Partido de Juan B. Alberdi, al noroeste bonaerense. Nuevamente, los argumentos para obtener la financiación y mejorar las condiciones de vida de sus poblaciones, recaían sobre la contribución que aportaban en términos productivos a la región ${ }^{61}$.

En el norte de Buenos Aires, el partido de Pergamino también solicitaba mejores caminos para conectar a la localidad con el trazado existente de las rutas nacionales y la incidencia de su producción era nuevamente remarcada en los fundamentos del proyecto de ley:

«El partido de Pergamino constituye una cabal expresión de la floreciente pujanza económica de la zona norte de nuestra Provincia (...)

De ello, son fiel testigo los índices estadísticos agropecuarios, que acreditan para la región que nos ocupa altos porcentajes de producción (...)

\footnotetext{
59 CDBA, 1958, p. 309.

${ }^{60}$ CDBA, 1958, p. 1406.

${ }^{61}$ CDBA, 1960, p. 733.
} 
Pero, al llegar a determinada condición en su avance, ha resultado obstructora de su progreso la dificultad en la comercialización que resulta para Alfonso de la falta de adecuados medios de comunicación. Y es de capital importancia en este sentido la solución del problema que se plantea permanentemente, y agravado en la época lluviosa del año, por el camino de acceso de la localidad a la ruta nacional N. ${ }^{\circ} 8 »^{62}$.

Otro eje sobre el cual se hizo hincapié, aunque no tuvo la misma repercusión en la gestión de Alende, pero sí durante los años del gobernador Marini, fue la educación rural. Entre 1958 y 1961 se presentaron una serie de propuestas para la creación de escuelas rurales especializadas en agricultura o lechería en localidades como Laprida (escuela agrícola-ganadera en 1958), Junín (escuela agrotécnica en 1958), Vedia (tambo modelo/escuela de lechería en 1959/60) o Pila (escuela granja y tambo modelo en 1961). Aunque no se concretaron muchos de estos proyectos y se conservaron la mayoría de los establecimientos existentes, los fundamentos coincidieron en la importancia de arraigar a la población local. Sólo por citar algunos extractos de los debates parlamentarios, para el caso de Pila se afirmaba que:

Desde hace años se nota una sensible disminución de su población, lo que resulta evidente constituye la consecuencia inmediata de la falta de fuentes de capacitación y trabajo para los jóvenes residentes de la zona, que se ven obligados a emigrar a otras partes en busca de mejores y más promisorios horizontes, para iniciar sus actividades» ${ }^{63}$.

En el área de salud, se observan una serie de esfuerzos por acercar infraestructura y servicios al interior provincial agropecuario, aunque no se reproduce la misma inercia observada en rutas y caminos. En 1958 distintos diputados oficialistas y de la oposición propusieron la elaboración de un censo sanitario para la población rural y la construcción de salas de primeros auxilios y dispensarios. Por otra parte, el diputado de la UCRI por la quinta sección electoral, Narciso Yugán, presentó un proyecto de ley ese mismo año que contemplaba la adquisición de automóviles para médicos rurales. Los argumentos fueron los siguientes:

«Con el mismo objeto de facilitar los medios para que la asistencia médica privada cumpla adecuadamente sus fines en las zonas rurales,

62 CDBA, 1960, pp. 888-889.

63 CDBA, 1961, p. 1647. 
requiere del Poder Ejecutivo las gestiones conducentes al otorgamiento de un régimen de prioridad para los profesionales mencionados, en la provisión de las unidades que salen a la venta pública» ${ }^{64}$.

Un planteo similar realizaba en su juventud Raúl Ricardo Alfonsín, en representación de la UCRP por la quinta sección junto con Horacio Néstor Ferro - diputado por la séptima sección - cuando presentaron un proyecto de ley que contemplaba el otorgamiento de créditos para la instalación de consultorios médicos y odontológicos en zonas rurales: «quienes desde hace años estamos en la campaña, conocemos el panorama que ofrece la medicina que allí se ejerce y sabemos que es muy difícil renovar los cuadros de médicos rurales (...) Hoy día la instalación de un consultorio es un asunto serio cuando se ve reflejado en la facturación correspondiente» ${ }^{65}$.

Otra «cuestión» en la agenda parlamentaria de la intransigencia radical fue la energía, en particular la electrificación rural. A fines de 1958, se presentó en ambas Cámaras un plan de obras eléctricas para la provincia de Buenos Aires autorizando inversiones para acercar la infraestructura mínima necesaria a un mayor número de localidades. Se proyectaron obras para ampliar la capacidad de generación de energía de las centrales y subestaciones de distribución eléctrica ${ }^{66}$. Las cooperativas eléctricas, presentes desde 1920 en las zonas rurales para acercar la energía a espacios con baja densidad poblacional, tenían una participación destacada en el proyecto oficial.

Algunos autores afirman que a fines de 1950 y principios de 1960 la dirigencia provincial - preocupada por las migraciones del campo a la ciudad - confiaba en que los proyectos de electrificación rural «en materia de interconexión - conexión simultánea y recíproca de las instalaciones de producción y consumo-, favorecerían el desarrollo económicoregional y la promoción sociocultural de los espacios rurales» ${ }^{67}$. Por el contrario, no se observan planes integrales para la provisión de cloacas y aguas corrientes en las localidades del interior, cuestión solicitada por algunos diputados provinciales.

\footnotetext{
64 CDBA, 1958, p. 1603.

65 CDBA, 1958, p. 1650.

66 CDBA, 1958, pp. 3264-3270.

67 Jacinto y Nogar, 2009-2010, p. 68.
} 
Las comunicaciones en el interior provincial se fortalecieron con la instalación de nuevos tendidos telefónicos y con la progresiva llegada del teléfono público a territorios que excedían la urbanización de los pueblos. En el partido de Lobos solicitaban en 1960 la instalación de teléfonos públicos en uno de sus parajes y justificaban su necesidad de la siguiente manera:

«La localidad de Las Chacras, ubicada en la línea del ferrocarril General Roca, del partido de Lobos, abriga una población que por su número da la pauta de su importante desenvolvimiento en las explotaciones agrícolo-ganaderas (...)

La falta de un teléfono público en una población de esta importancia trae enormes perjuicios para su desarrollo, creando para sus habitantes graves inconvenientes para su inmediata comunicación con otros centros. Teniendo presente, por otra parte, que en épocas de lluvia es imposible la comunicación por el mal estado de los caminos, no escapará al criterio de los señores legisladores la urgencia de la instalación del mencionado servicio público» ${ }^{68}$.

El pasaje no solo introduce los fundamentos presentados para que se concreten las obras necesarias; también ilustra las dificultades que debieron superar los actores productivos del agro bonaerense en una localidad ubicada a menos de 100 kilómetros de la capital federal. Una situación análoga se vivía en el sur provincial dentro del partido de Bahía Blanca, que a fines de ese mismo año solicitaba la instalación de un teléfono público en Villa Sánchez: «si bien es cierto que el teléfono ha sido superado en cuanto a la técnica y a la magnitud de su proyección por otros sistemas de comunicación, no es menos cierto que de ninguna manera ha pasado a segundo plano como elemento necesario, cuando no imprescindible, para la vida moderna» ${ }^{6}$.

Sin embargo y a pesar de estos proyectos, el discurso modernizador del desarrollismo se concentró en poner a disposición del productor la tierra, la técnica y la maquinaria moderna antes que en mejorar el bienestar en el mundo rural. Muchas de estas propuestas, además, no se concretaron. Si bien los líderes de la UCR reivindicaron y reclamaron en los debates parlamentarios buena parte de las demandas históricas de los sectores

68 CDBA, 1960, p. 732.

Historia Contemporánea 55: 637-668 
postergados en el agro, las políticas instrumentadas por el Poder Ejecutivo resultaron, cuanto menos, insuficientes.

\section{Anselmo Marini y el radicalismo del pueblo (1963-1966)}

Luego del golpe de Estado de 1962 se sucedieron cinco interventores federales en la provincia de Buenos Aires: Jorge Bermudez Emparanaza, Roberto Etchepareborda, Ceferino Merbilhaa, Felix Trigo Viera y Francisco A. Imaz. En 1963 se realizaron los comicios electorales nacionales y provinciales. Triunfó en ambos casos la Unión Cívica Radical del Pueblo. En Buenos Aires, la fórmula Anselmo Marini ${ }^{70}$-Ricardo Lavalle obtuvo el $25 \%$ con 774.955 votos, contra el binomio de la UCRI integrado por Julio Oyhanarte-Juan Carlos Manes que obtuvo el 19,4\% con 599.494 sufragios. Al igual que en las elecciones nacionales, el voto en blanco fue representativo y significó el 23\% - 716.417 votos- del electorado, exponiendo la gravitación de Perón desde el exilio en la política nacional así como del movimiento peronista organizado ${ }^{71}$.

La gestión del gobernador Marini adquirió un sesgo keynesiano ${ }^{72}$. Promulgó la Ley de Promoción Industrial para descentralizar y radicar nuevas plantas industriales a cambio de beneficios fiscales ${ }^{73}$. Destinó buena parte de los fondos públicos para construir obras hidráulicas y dar respuesta a las inundaciones, sobre todo en el área del Gran Buenos Aires. La modificación de la Carta Orgánica del Banco Provincia ${ }^{74}$ durante su gestón permitió «disponer que el 50\% de las utilidades netas de la institución se reinvirtiesen en el acrecentamiento de su cartera hipotecaria». En materia de salud «se autorizaba por ley al gobierno a instaurar una re-

70 Anselmo Marini: abogado y político. Nació el 18 de noviembre de 1906 en La Plata, provincia de Buenos Aires. Curso estudios en la Facultad de Ciencias Jurídicas y Sociales de la UNLP. En 1929 es electo presidente de la Federación universitaria platense. Ocupo diversos cargos legislativos como diputado provincial y nacional en la UCR, hasta alcanzar en 1963 la gobernación de la provincia de Buenos Aires. Información extraída de la nota del profesor César Arrondo en Diagonales.com http://www.diagonales.com/ diagonales/145920-anselmo-marini.html

71 James, 2007.

72 Arrondo, 2013.

73 Rapoport, 2006.

${ }^{74}$ De Paula y Girbal-Blacha, 1998. 
gionalización sanitaria provincial» ${ }^{75}$. Estas medidas apuntaban a resolver - aunque de manera parcial - las demandas de mayor bienestar.

Anselmo Marini fue acompañado en la cartera de Asuntos Agrarios por Alberto Zubiaurre, quien impulsó medidas destinadas a reactivar la producción agropecuaria bonaerense, como el plan ganadero establecido por el decreto 66/63. En 1964 los diputados bonaerenses discutieron la importancia de aprovechar mejor las zonas agropecuarias: «la explotación intensa y sin sujeción a normas culturales adecuadas, disminuye su producción efectiva y hace peligrar sus posibilidades potenciales. Problemas como el del empobrecimiento de tierras, erosión hídrica y eólica, se han venido agravando año tras año debido a la falta de racionalidad en las formas de explotación ${ }^{76}$.

El problema ganadero tuvo un lugar destacado en este debate, que desde una óptica económica, buscaba mejorar las condiciones de vida en el agro provincial a partir de una mayor rentabilidad utilizando nuevos criterios productivos:

«Circunstancias similares se dan en la ganadería, donde a pesar de los mejoramientos de planteles, es notoria la deficiente o inadecuada explotación de pasturas, antieconómica organización de potreros y aguadas, falta de previsión ante fenómenos cíclicos previsibles (...) Imprescindible es por lo tanto, actuar con premura. Necesitamos racionalizar y planear nuestra producción. Realizar para ello los estudios y experiencias aconsejables. Aplicar las conclusiones con método y tenacidad» ${ }^{77}$.

Modernizar el agro fue otro objetivo perseguido por el gobierno provincial. El decreto 11.660 publicado en el Boletín Oficial el 11 de octubre de 1963 rubricaba un convenio entre el Instituto Nacional de Tecnología Agropecuaria y el Ministerio de Asuntos Agrarios para la creación del Consejo de Tecnología Agropecuaria de la provincia de Buenos Aires. En el decreto se dejaba asentada la importancia de «un Consejo que actúe como nexo para canalizar la actividad que se desarrolla, con el propósito de lograr los objetivos reseñados, en los cuales debe incluirse a las fuerzas productoras con la finalidad de darles participación en los planes de que son destinatarios» ${ }^{78}$.

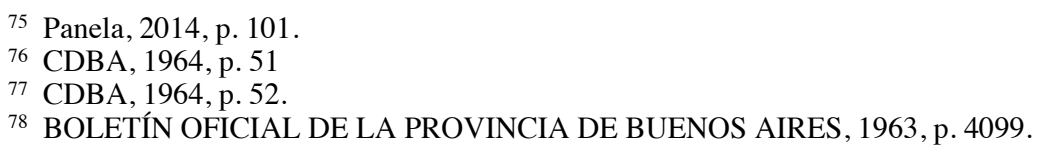


La orientación de la provincia de Buenos Aires en materia tecnológica fue coincidente con las propuestas del radicalismo del pueblo a nivel nacional y adquirió relevancia en la segunda mitad de la década de 1960, cuando «al tiempo que se favorecía la producción nacional se impulsó la instalación de filiales extranjeras dedicadas a la fabricación de tractores, lo que hacia finales de la década posibilitaba el autoabastecimiento en este rubro» ${ }^{79}$.

Como sostienen algunos autores, durante el gobierno de Illia «la política agraria tuvo como propósito explícito el aumento de la producción, siendo casi nulas las propuestas distribucionistas, orientadas a afectar la disponibilidad previa de la tierra» ${ }^{80}$. La utilización de la expropiación como herramienta reformista, se diferenció notablemente del proyecto desarrollista provincial que entre 1958 y 1962, propuso la expropiación y colonización de 500.000 hectáreas para redistribuir la propiedad de la tie$\mathrm{rra}^{81}$. En este caso el bienestar era presentado como una cuestión cuantificable y medible que se expresaba en la mejora de la producción y tenía una repercusión positiva en la vida cotidiana de los sujetos agrarios.

Conforme a la ley 6264, el Ministerio de Asuntos agrarios bonaerense, encaró un proceso de colonización privada y se propiciaba la colonización privada desde el mensuario oficial Asuntos Agrarios. En la localidad de Carlos Tejedor, por ejemplo, se firmó un contrato el 29 de enero de 1964 entre arrendatarios y propietarios del campo «Merlo» en el Instituto Agrario de la Provincia de Buenos Aires ${ }^{82}$. La propiedad contaba con 1.600 hectáreas y se convinieron las siguientes cuestiones:

«mantener en todas sus vigencias, con sus obligaciones y derechos, el boleto de compra-venta suscripto el 2 de julio de 1963 (...) que los propietarios aceptan someter a estudio y consideración del Instituto Agrario las condiciones de venta fijada en el boleto de compra-venta aludida (...) dejando las partes actuantes expresa constancia que el mismo no importa compromiso alguno por parte de IABA que, en última instancia y de acuerdo a los resultados obtenidos de los estudios técnico-legales del predio, determinará o no su colonización privada» ${ }^{83}$.

\footnotetext{
79 Barsky y Gelman, 2009, p. 394.

80 Lázzaro, 2005, p. 206.

81 Lázzaro, 2008.

82 Blanco, 2007.

83 Asuntos Agrarios, 1964, p. 1.
} 
En lo que refiere al accionar estatal tendiente a mejorar el bienestar de los sujetos rurales, no existió una orientación específica ni tampoco un proceso lineal o continuador de las metas y objetivos propuestos por el desarrollismo bonaerense entre 1958 y 1962. Los proyectos de pavimentación y construcción de nuevos caminos, presentes en la gestión de Alende pierden impulso en estos años. La educación rural, por el contrario, adquirió gran protagonismo en los debates parlamentarios, sobre todo en la Cámara de diputados. El área de salud fue una de las prioritarias en la política trazada por Anselmo Marini.

Además de los proyectos para la creación de escuelas agrícolo-ganaderas (que tuvieron un éxito relativo) en la provincia, se propuso la transmisión radial de lecciones para las escuelas rurales. El proyecto no era una novedad y sus antecedentes pueden rastrearse en la década de 1940 en el Anuario Rural de la Provincia de Buenos Aires ${ }^{84}$. Lo que se pretendía era reparar ciertas limitaciones de la enseñanza en el medio rural bonaerense. Los fundamentos del diputado Manuel Pardo se expresaban en este sentido y la idea de capacitar a los maestros rurales era compatible y necesaria para alcanzar la anhelada modernización:

«Sabido es que en una importante extensión del territorio provincial se imparte la enseñanza primaria en las escuelas rurales llamadas también «unitarias». La característica principal de estas escuelas es que, en su mayoría, están atendidas por un solo maestro, el que debe ocuparse de dar enseñanza conjunta a un grupo de niños con programas escolares de distinto nivel (...)

Es indudable que en estas condiciones, la capacitación técnica de este tipo de maestro tiene exigencias particulares, cual es por ejemplo, la de poder instruir simultáneamente a niños que cursan el primer grado inferior y otros en los distintos grados restantes» ${ }^{85}$.

La educación en el agro provincial era complementada con el trabajo de extensión realizado por el Instituto Nacional de Tecnología Agropecuaria (INTA), que en estos años difundió la mecanización, tecnificación e innovación en el agro. Las propuestas del área de extensión iban desde una variedad de cursos y capacitaciones (para tractoristas, contra la bru-

${ }^{84}$ MINISTERIO DE OBRAS PÚBLICAS DE LA PROVINCIA DE BUENOS AIRES, 1941, pp. 515-519.

${ }^{85}$ CDBA, 1965, p. 116. 
celosis, campañas agrícolas regionales, mejoramiento de pasturas, entre otros), hasta la difusión de folletos y de programas como los Clubes del Hogar Rural y los Clubes 4-A, orientados a las mujeres y los jóvenes rurales, respectivamente ${ }^{86}$.

En el tema de las comunicaciones, se produjeron ciertas continuidades para mejorar las condiciones de vida en el interior provincial, acercando el teléfono público a las zonas rurales. En 1965 el diputado peronista Francisco Vistalli propuso la instalación de varios teléfonos públicos en la localidad de Tandil. El proyecto recibió el apoyo de la UCRP y se observa en sus argumentos el reclamo para el pueblo:

«es imprescindible la instalación de tres cabinas telefónicas para uso de la población ya que, por razones de orden técnico, Teléfonos del Estado no instala en esa localidad teléfonos ni en forma comercial ni industrial (...) Es necesario terminar con ese aislamiento, pues existen en funcionamiento, pero en forma particular, solo tres teléfonos que específicamente pueden calificarse de orden privado; uno en una panadería; uno en la subcomisaria y otro en la sociedad de fomento Unión y Progreso» ${ }^{87}$.

Este registro textual advierte sobre las limitaciones existentes entre mediados de 1950 y principios de 1960 en la infraestructura comunicacional de las localidades del interior provincial. Al igual que sucedía en otras localidades como Bahía Blanca o Lobos, los reclamos presentados por otros diputados apuntaban a elevar los niveles de vida en estas localidades. En el caso de Tandil, la situación era más compleja para las zonas productivas que estaban alejadas del ejido urbano: «las nuevas poblaciones que por la importancia de su núcleo y distancia que las separan del centro urbano; necesariamente no pueden quedar aisladas, por la falta de medio de comunicación como lo es el moderno servicio telefónico» ${ }^{88}$.

La incapacidad de establecer prioridades de mediano y largo plazo de los sectores políticos con capacidad real de acceder y alternar en el poder provincial, dieron lugar a este tipo de discontinuidades e inconsistencias en las políticas públicas. Y, por consiguiente, la interpretación de lo que debía ser el bienestar en el agro. Ésta no es clara en ninguna de las dos

\footnotetext{
86 Gutierrez, 2009.

87 CDBA, 1965, p. 767.

${ }^{88}$ CDBA, 1965, p. 768.
} 
gestiones analizadas y, posiblemente, se vio alterada por las tensiones no resueltas entre los partidos políticos, las corporaciones económicas y sindicales, las Fuerzas Armadas y Perón en el exilio.

La «cuestión social rural» no se presentó como un tema en sí mismo en la gestión de políticas públicas. Se discutió con mayor profundidad el destino de los excedentes agrarios pampeanos, tema presente inclusive durante el gobierno del general Juan Carlos Onganía, que derrocó a Arturo Illia en junio de $1966^{89}$. Las consignas económicas aperturistas en materia económica impulsadas por el Estado «burocrático-autoritario», ${ }^{90}$ dispusieron el vencimiento de los contratos de arrendamiento y aparcerías. Esto generó graves perjuicios a los sectores no propietarios y clausuró un proceso de casi tres décadas de reivindicaciones sectoriales, que a pesar de sus avances y retrocesos, garantizó un piso de estabilidad en las condiciones de vida de los arrendatarios y trabajadores rurales.

\section{Reflexiones}

Entre 1946 y 1955 el peronismo logró conducir la política y la economía nacional gracias a un complejo aparato estatal intervencionista y planificador, que proponía una mayor distribución de la riqueza sobre la base de la «justicia social». En el período que se extiende desde 1955 hasta 1966, la fragilidad institucional sumada a los conflictos de intereses entre el sector agroexportador y las industrias sustitutivas de importación manifestadas en la puja distributiva, pusieron en tensión las bases del bienestar alcanzado por los sectores asalariados en el gobierno de Perón. Las tensiones de un «juego» político con reglas poco claras y con «jugadores» que operaron de manera premeditada o fortuita contra la estabilidad democrática y la construcción de consensos, complementan la caracterización del período.

En la provincia de Buenos Aires, Oscar Alende y Anselmo Marini representaron a los dos sectores de una Unión Cívica Radical dividida. En ambos casos, la modernización y el desarrollo del sector agrario fueron objetivos centrales, aunque las estrategias y el tipo de políticas públicas desplegadas fueron diferentes. La incorporación del peronismo a la participación política fue el principal problema a resolver, tanto a nivel na-

\footnotetext{
89 Lázzaro, 2005.

90 O’Donnel, 1997.
} 
cional como en la escala provincial. La impugnación de un sector sobre el otro dificultó el ejercicio estable de los programas de gobierno y la formulación de políticas de mediano y largo plazo.

Pero en ninguno de los dos casos fueron claros en sus propuestas sobre lo que significaba el bienestar y el rol del Estado en esta cuestión, más allá de las alusiones genéricas a la importancia que tenía perseguir el bienestar general de la población. La mejora en las condiciones de vida de los sectores rurales abarcaba una amplia serie de cuestiones para los proyectos políticos radicales. Infraestructura vial, educación, salud, colonización y electrificación rural fueron tópicos comunes a los dos gobiernos radicales de la provincia de Buenos Aires entre 1958 y 1966.

Las decisiones macroeconómicas del período en cuestión, coincidieron en una progresiva liberalización de la economía. Sin embargo, se produjeron oscilaciones/tensiones en el equilibrio del gasto público, pasando por momentos de expansión - políticas de pleno empleo- y contracción del mismo - reducción del personal estatal-. La falta de consensos políticos en la toma de decisiones a mediano y largo plazo observado en los debates parlamentario, derivó en proyectos inconclusos o truncos para mejorar las condiciones de vida en el agro bonaerense.

En el plan integral de reforma provincial encarado por Alende a partir de 1959, las consignas de reforma agraria y tributaria tuvieron un considerable efecto simbólico y práctico. Expropiaciones moderadas, colonización y presión tributaria fueron los instrumentos elegidos para modificar la estructura de tenencia de la tierra. La creación de una burocracia especializada, encarnada en la Junta de Planificación Económica de Buenos Aires y el rol central del Estado en el proceso de transformación agraria, ilustran la orientación desarrollista del programa político intransigente. Los créditos y beneficios otorgados a las cooperativas rurales complementan el programa reformista.

Distinta es la situación en el gobierno de Marini. Entonces se pone atención en incrementar la producción rural y se circunscribe el debate a la cuestión de la distribución de los excedentes agrarios. La modernización es el concepto vertebrador del programa, basado en la asistencia a los productores y su incorporación en el proceso de transferencia técnica. A partir de 1963 el Estado comenzó a perder protagonismo en el proceso de redistribución de la propiedad de la tierra y se reforzaron los instrumentos legales para acelerar la colonización privada. Salud y educación fueron los pilares de las políticas de bienestar social a nivel provincial de la Unión Cívica Radical del Pueblo. 
Las propuestas para mejorar las condiciones de vida en el agro tuvieron un alcance limitado. Se observaron algunas mejoras en las comunicaciones a lo largo de todo período analizado, la ejecución de obras de infraestructura vial y eléctrica desde 1958 hasta 1960 y una discursividad orientada en beneficio de la educación rural entre 1963 y 1966. Sin embargo, en la mayoría de los casos el accionar del Estado y las solicitudes de los representantes enfatizaban la importancia productiva que tenían las distintas localidades y los beneficios económicos que traerían aparejadas esas obras.

Llama la atención que en las fuentes analizadas, las alusiones de los principales actores políticos no estuviesen centradas en mejorar el bienestar rural como una meta en sí misma. Por el contrario fueron aisladas y escasas.

Los planes nacionales de modernización agraria apuntaron a mecanizar y tecnificar las labores y tuvieron consecuencias en el proceso de transformaciones de las familias rurales bonaerenses, que explotaban un número significativo de unidades productivas. El conocimiento experto comenzó a ocupar un rol protagónico en estos cambios y la creación de nuevas instituciones con una burocracia especializada garantizó su continuidad. Las tensiones entre reforma y estabilidad caracterizaron esta etapa de la historia argentina y del principal distrito rural del país. El panorama nacional sin el apoyo de Perón desde fines de 1958 complicó la situación.

\section{Fuentes}

Asuntos Agrarios, La Plata, mayo-junio 1958, N. ${ }^{\circ}$ 57-58, p. 3; septiembre 1958, N. ${ }^{\circ} 61$, p. 1 ; enero de 1964, N. $^{\circ} 125$, p. 1 .

Biblioteca Nacional. Fondo Reservado Arturo Frondizi, Anotaciones sobre colonización y problemas de la tierra, Secretaría de Estado de Agricultura y Ganadería de la Nación, Buenos Aires, 1959.

Biblioteca Nacional. Fondo Reservado Arturo Frondizi, Reforma Agraria. Aspectos económicos y jurídicos, Buenos Aires, República Argentina, s/f.

Boletín Oficial De la Provincia De Buenos Aires, viernes 11 de octubre de 1963.

Cámara De Diputados De Buenos Aires (CDBA), Diario de sesiones, $100 .{ }^{\circ}$ período, año 1958-1959, 1ra sesión ordinaria, mayo 8 de 1958, p. 101.

-, 100 ${ }^{\circ}$ período, año 1958-1959, 4ta sesión ordinaria, mayo 29 de 1958, p. 309. 
-, 100. período, año 1958-1959, 17ma sesión ordinaria, agosto 13 de 1958, p. 1406.

-, 100. ${ }^{\circ}$ período, año 1958-1959, 18va sesión ordinaria, agosto 14 de 1958, p. 1603.

-, $100{ }^{\circ}$ período, año 1958-1959, 19na sesión ordinaria, agosto 20 de 1958, p. 1650.

-, $100{ }^{\circ}$ período, año 1958-1959, 2da sesión extraordinaria, diciembre 16 de 1958, pp. 3264-3270.

-, 102. período, año 1960-1961, 11 ra sesión ordinaria, julio 21 de 1960, p. 732 .

-, 102. ${ }^{\circ}$ período, año 1960-1961, 11 ra sesión ordinaria, julio 21 de 1960, p. 733.

-, 102. ${ }^{\circ}$ período, año 1960-1961, 13ra sesión ordinaria, agosto 4 de 1960, pp. 888-889.

-, 102. ${ }^{\circ}$ período, año 1960-1961, 11ra sesión de prórroga, octubre 28 de 1960, p. 2220.

-, 103. período, año 1961-1962, 11 ra sesión ordinaria, agosto 31 de 1961, p. 1647.

-, 105. ${ }^{\circ}$ período, año 1964-1965, 1ra sesión ordinaria, mayo 14 de 1964, p. 51

-, 105. período, año 1964-1965, 1ra sesión ordinaria, mayo 14 de 1964, p. 52.

-, 106. período, año 1965-1966, 1ra sesión ordinaria, mayo 1 de 1965, p. 116.

-, 106. período, año 1965-1966, 9na sesión ordinaria, julio 22 de 1965, p. 767.

-, 106..$^{\circ}$ período, año 1965-1966, 9na sesión ordinaria, julio 22 de 1965, p. 768.

Consejo Nacional de Desarrollo (CONADE), Tenencia de la tierra, Consejo Federal de Inversiones, Buenos Aires, 1964.

DiReCCIÓN DE PRENSA, Síntesis de problemas y soluciones expuestos durante las giras del gobernador de Buenos Aires, La Plata, 1958.

Gobierno de la Provincia De Buenos Aires, Reforma Agraria. Reunión en Rojas. Discurso del señor gobernador doctor Oscar Alende, La Plata, 1959. http://www.diagonales.com/diagonales/145920-anselmo-marini.html http://www.eumed.net/cursecon/economistas/ferrer.htm http://www.gob.gba.gov.ar/legislacion/legislacion/l-6022.html

KUGLER, Walter, Ideas que animaran la acción de la Secretaría de Agricultura y Ganadería en el período 1963-1969, SECRETARÍA DE AgRicultura y GANADERía DE LA NACIÓN, Buenos Aires, octubre de 1963.

Ministerio de Obras Públicas de la Provincia de Buenos Aires, Anuario Rural 1941, Dirección de Agricultura, Ganadería e Industrias, La Plata, Año IX, N. ${ }^{\circ} 9$.

PRESIDENCIA DE LA NACión/CONADE, Programas de desarrollo agropecuario. Tema de divulgación interna $N .^{\circ} 32$, Buenos Aires, s/f. 
Política, acción estatal y bienestar en el agro. Buenos Aires (1958-1966)

\section{Bibliografía}

Abad de Santillan, Diego, Gran enciclopedia argentina, EDIAR, Buenos Aires, 1956.

Adamovsky, Ezquiel, Historia de la clase media Argentina, Planeta, Buenos Aires, 2009.

AELO, Oscar, «Partido y Estado en el primer peronismo», en BARRENECHE, Osvaldo (Dir.), Historia de la provincia de Buenos Aires. Del Primer peronismo a la crisis de 2001, Edhasa, Buenos Aires, 2014.

Arrondo, César, Anselmo Marini: un gobierno republicano en tiempos de autoritarismo, Publicaciones del Archivo Histórico de la provincia de Buenos Aires, La Plata, 2013.

Azcuy Ameghino, Eduardo y Martínez Dougnac, Gabriela, «La agricultura familiar pampeana no es un mito, pero es cada vez más un recuerdo», en LóPEZ CASTRO, Natalia y PRIVIDERA, Guido (comps.), Repensar la agricultura familiar: aportes para desentrañar la complejidad agraria pampeana, CICCUS, Buenos Aires, 2010.

BALSA, Javier, «Transformaciones en los modos de vida de los chacareros bonaerenses en la segunda mitad del siglo XX y su contraste con los farmers del corn belt norteamericano», en GALAFASSI, Guido (Comp.), El campo diverso. Enfoques y perspectivas de la Argentina agraria del siglo XX, Editorial UNQ, Bernal, 2004.

BALSA, Javier, El desvanecimiento del mundo chacarero. Transformaciones sociales en la agricultura bonaerense (1937-1988), Editorial UNQ, Bernal, 2006.

BARSKY, Osvaldo y Gelman, Jorge, Historia del agro argentino. Desde la conquista hasta comienzos del siglo XXI, Sudamericana, Buenos Aires, 2009.

BAyle, Paola y Diez, Agustina, «La Revista de Desarrollo Económico en la coyuntura de 1958-1960», en BiAgini, Hugo y RoIG, Arturo (Dir.), El pensamiento alternativo en la Argentina de siglo XX: obrerismo y justicia social (1930-1960), Biblos, Buenos Aires, 2006.

Blanco, Mónica, Reforma en el agro pampeano. Arrendamiento, propiedad y legislación agraria en la provincia de Buenos Aires (1940-1960), Editorial UNQ, 2007.

CAMPI, Mercedes, Tierra, tecnología e innovación. El desarrollo agrario pampeano en el largo plazo, 1860-2007, Prometeo, Buenos Aires, 2011.

De Paula, Alberto y Girbal-Blacha, Noemí María, Historia del Banco de la Provincia de Buenos Aires 1822-1997, ediciones Macchi, Buenos Aires, 1998.

GALlo, Ricardo, 1956-1958. Balbín, Frondizi y la división del radicalismo, Editorial de Belgrano, Buenos Aires, 1983.

García SEBASTIANI, Marcela, Los antiperonistas en la Argentina peronista, Prometeo, Buenos Aires, 2005. 
Girbal-Blacha, Noemí María, Ayer y hoy de la Argentina Rural. Gritos y susurros del poder económico (1880-1997), Editorial Página 12, Buenos Aires, 1998.

Girbal-Blacha, Noemí María, Mitos, paradojas y realidades en la Argentina peronista (1946-1955), Editorial UNQ, Buenos Aires, 2011.

GuTIERREZ, Talía, «Agro pampeano y roles familiares en la década de 1960», Mundo Agrario, Vol. 10, N. ${ }^{\circ}$ 19, segundo semestre de 2009.

GuTIERREZ, Talía, Educación, agro y sociedad. Políticas educativas agraria en la región pampeana. 1897-1955, Editorial UNQ, Bernal, 2007.

HABermas, Jurgen, Ensayos políticos, Ediciones Península, Barcelona, 1988.

JACINTO, Guillermina y NOGAR, Maria, «Electrificación rural, desarrollo territorial y pequeñas localidades. El caso de Tandil (Provincia de Buenos Aires, Argentina)», Breves contribuciones del IEG, N. . 21, Año 2009-2010, pp. 6084.

JAMES, Daniel (Dir.), Nueva Historia Argentina. Violencia, proscripción y autoritarismo (1955-1976), Sudamericana, Buenos Aires, 2007.

JoRge NAVARRo, Marcelo, «Educación técnica rural en la Argentina. 1910-1960», Revista Escuela de Historia, Vol. 11, N. . 2, 2012, pp. 1-21.

KVATERNIK, Eugenio, «Sobre partidos y democracia en la Argentina entre 1955 y 1966», Desarrollo Económico, Vol. 18, N. . 71, octubre-diciembre 1978.

LATTUADA, Mario, «El debate impositivo sobre el sector agropecuario argentino», Anuario del Centro de Estudios Históricos, N. ${ }^{\circ}$ 8, Año 8, Córdoba, 2008, pp. 107-138.

LÁZZARO, Silvia, «Desarrollismo y cuestión agraria durante el gobierno de Arturo Frondizi», en Galafassiï, Guido; BonNET, Alberto y ZARRILli, Adrián, Modernización y crisis, Editorial UNQ, Bernal, 2002.

LÁZZARO, Silvia, «El Estado y las políticas agrarias: concepciones y estrategias en el contexto de crisis de hegemonía de la clase dominante (1955-1969)», en LÁZZARO, Silvia y GALAFASSI, Guido, Sujetos, política y representaciones del mundo rural. Argentina 1930-1975, Siglo XXI, Buenos Aires, 2005.

LÁZZARO, Silvia, «El impuesto al latifundio en la provincia de Buenos Aires durante las décadas de 1940 y 1950», Anuario de Historia Argentina, ‥ ${ }^{\circ}$ 14, 2014.

LÁZZARO, Silvia, «Estado, desarrollo y reforma agraria en la provincia de Buenos Aires (1958-1962)», Anuario del Centro de Estudios Históricos, Año 8, N. ${ }^{\circ}$ 8, Córdoba, 2008, pp. 85-106.

Mateo, Graciela, Cooperativas agrarias y peronismo, CICCUS, Buenos Aires, 2012.

MuRMIs, Miguel y PORTANTIERo, Juan Carlos, Estudios sobre los orígenes del peronismo, Siglo XXI, Buenos Aires, 2004.

Nosiglia, Julio, El desarrollismo, CEAL, Buenos Aires, 1983.

Novick, Susana, IAPI. Auge y decadencia, Catálogos, Buenos Aires, 2004. 
O’Donnel, Guillermo, Contrapuntos. Ensayos escogidos sobre autoritarismo y democratización, Paidos, Buenos Aires, 1997.

Offe, Clauss, Contradicciones en el Estado de Bienestar, Alianza Universidad, Madrid, 1990.

PANELA, Claudio, «Política bonaerense y gestiones gubernativas, 1943-2001», en B ARRENEChe Osvaldo (Dir. de tomo), Historia de la provincia de Buenos Aires, Tomo 5, Edhasa, Buenos Aires, 2014.

PIcó, Josep, Teorías sobre el Estado de Bienestar, Siglo XXI, España, 1990.

PortantiEro, Juan Carlos, «Economía y política en la crisis argentina: 19581973», Revista Mexicana de sociología, Vol. 39, ․․ 2, abril-junio 1977, pp. 531-565.

RAPOPORT, Mario, Historia económica, política y social de la Argentina (18802003), Ariel, Buenos Aires, 2006.

RougIER, Marcelo, «Economía y desempeño industrial», en BARRENECHE, Osvaldo (Dir. de tomo), Historia de la provincia de Buenos Aires, Tomo 5, Edhasa, Buenos Aires, 2014.

RougIER, Marcelo, Aldo Ferrer y sus días. Ideas, trayectorias y recuerdos de un economista, Lenguaje Claro, Buenos Aires, 2015.

RouQuiE, Alain, Poder militar y sociedad política en la Argentina, Emece, Buenos Aires, 1981.

RouQUIE, Alain, Radicales y desarrollistas, Schapire editor, Buenos Aires, 1975.

SAlomón, Alejandra, El peronismo en clave rural y local. Buenos Aires, 1945 1955, Editorial UNQ, Bernal, 2012.

SidicARo, Ricardo, Los tres peronismos, Siglo XXI, Buenos Aires, 2002.

Smulovitz, Catalina, «El sistema de partidos en la Argentina: modelo para armar», Desarrollo económico, Vol. 26, N. ${ }^{\circ}$ 101, abril-junio 1986.

Smulovitz, Catalina, «En búsqueda de la fórmula perdida: Argentina, 19551966», Desarrollo Económico, Vol. 31, N. ${ }^{\circ}$ 121, abril-junio 1991.

SPINELLI, María Estella, «La "otra multitud”. Las movilizaciones antiperonistas durante la "libertadora"», Desarrollo Económico, V. 43, N. ' 172, eneromarzo de 2004, 609-635.

SPINELLI, María Estella, «La construcción del Frente Nacional en la Argentina post-peronista, 1955-1958. ¿Una estrategia electoral o un proyecto político modernizador?», Revista de Estudios Interdisciplinarios de América Latina y el Caribe, Año III, N. ${ }^{\circ} 1,1992$.

Stropparo, Pablo, «Producción de conocimiento, contexto y políticas públicas. El caso de la Junta de Planificación Económica de la Provincia de Buenos Aires (1958-1960)», Revista Debate Público, Año 2, Nro. 4, 2012, pp. 115131.

TCACH, César y RodRíguez, Celso, Arturo Illia: un sueño breve. El rol del peronismo y de los Estados Unidos en el golpe militar de 1966, Edhasa, Buenos Aires, 2011. 
TCACH, César, «Golpes, proscripciones y partidos políticos», en JAMES, Daniel (Dir.), Nueva Historia Argentina. Violencia, proscripción y autoritarismo (1955-1976), Sudamericana, Buenos Aires, 2007.

TORRE, Juan Carlos, La vieja guarda sindical y Perón. Sobre los orígenes del peronismo, Editorial Untref, Buenos Aires, 2006.

ZARRILLI, Adrián, «Desregulación institucional, sofisticación financiera y accionar del Banco de la Provincia», en De Paula, Alberto y GiRbal-Blacha, Noemí, Historia del Banco de la Provincia de Buenos Aires 1822-1997, Ediciones Macchi, Buenos Aires, 1998.

\section{Datos del autor}

Maximiliano Ivickas Magallán (mivickas@gmail.com) es licenciado en Ciencias Sociales de la Universidad Nacional de Quilmes (UNQ) y doctorando en Ciencias Sociales y Humanas de la misma universidad. Becario doctoral del Consejo Nacional de Investigaciones Científicas y Técnicas (CONICET). Miembro del Consejo Asesor del Centro de Estudios de la Argentina Rural (CEAR) y del programa de investigación "La argentina rural de los siglos XX y XXI. Espacios regionales, transformaciones medioambientales, sujetos sociales y políticas públicas». 